\title{
Avaliação da função e da lesão renal: um desafio laboratorial
}

\section{Evaluation of renal function and damage: a laboratorial challenge}

Fábio L. Sodré1; Josete Conceição Barreto Costa²; José Carlos C. Lima'

\begin{tabular}{|c|c|}
\hline unitermos & \\
\hline $\begin{array}{l}\text { Função renal } \\
\text { Lesão renal } \\
\text { Taxa de filtração } \\
\text { glomerular } \\
\text { Testes laboratoriais }\end{array}$ & $\begin{array}{l}\text { Atualmente a doença renal é um grande problema de saúde pública, que acomete milhares de pessoas } \\
\text { no Brasil e no mundo. O estudo da função e dos diversos processos patológicos renais tem despertado o } \\
\text { interesse de muitos pesquisadores, principalmente no campo do desenvolvimento de testes que auxiliem } \\
\text { os médicos a estabelecer um diagnóstico precoce, classificar a doença de base, obter prognóstico seguro } \\
\text { e monitorar terapêutica medicamentosa. Neste artigo sete marcadores de função e de lesão renal são } \\
\text { avaliados: uréia, creatinina, cistatina C, proteinúria, dismorfismo eritrocitário, microalbuminúria e fração } \\
\text { hepática das proteínas ligadas a ácidos graxos. É apresentado um breve histórico da utilização clínica e da } \\
\text { fisiopatologia de cada um deles, seguidas de sua aplicabilidade e dos avanços técnicos e metodológicos } \\
\text { disponíveis. Apesar de melhorias terem sido conseguidas e incorporadas à prática laboratorial, nenhum } \\
\text { marcador atualmente disponível é completamente eficaz em analisar a função e/ou a lesão renal de } \\
\text { forma precisa, sendo imprescindível o conhecimento de todos eles para uma correta avaliação desses } \\
\text { testes comuns na rotina laboratorial. }\end{array}$ \\
\hline
\end{tabular}

abstract

Nowadays, renal disease is an important public health problem, affecting millions of people in Brazil and in the world. The study of renal function and renal pathologic processes has aroused the interest of researchers, mainly in the field of development of new assays that could aid physicians in establishing early diagnosis, better classifying the disease, obtaining better outcome and monitoring drug therapeutics. In this article, seven laboratory markers of renal function or damage are evaluated: urea, creatinine, cystatin C, proteinuria, dysmorphic erythrocytes, microalbuminuria and liver-type fatty acid binding protein ( $L-F A B P$ ). For each one of them, a short historical report of its clinical utility and physiopathology is presented. Then technical and methodological approaches are described as well as its utility in clinical management of kidney patients. Although improvements have been reached and incorporated in laboratorial practice, none of these markers is effective enough to define precisely kidney function and/or damage and an extensive understanding of all of these markers is crucial to correct evaluate renal function. key words

Renal function

Renal damage

Glomerular filtration rate

Laboratorial tests 


\section{Introdução}

A avaliação da função renal é um dos mais antigos desafios da medicina laboratorial. Muitos avanços foram feitos nesse campo desde a primeira dosagem de creatinina feita por Jaffe, em $1886^{(1)}$. Porém, ainda há espaço para o desenvolvimento de marcadores laboratoriais da função renal. É mais fácil compreender a avidez por esses marcadores quando se analisa o impacto da doença renal. No Brasil, onde sabidamente há problemas em registrar ocorrências médicas e não há uma base de dados confiável, fontes oficiais indicam existir, hoje, cerca de 1 a 4 milhões de portadores de insuficiência renal crônica (IRC) ${ }^{(2)}$. Nos Estados Unidos da América, onde os dados se afiguram mais confiáveis, a doença acomete entre 11 e 20 milhões de indivíduos ${ }^{(3)}$.

O impacto econômico dessa patologia é outra preocupação das autoridades em saúde pública, já que, além de muito dispendioso, o tratamento medicamentoso e dialítico praticamente alija os indivíduos em idade produtiva de sua capacidade laborativa, afetando o sistema de previdência pública e seguridade social. Logo, entendem-se as campanhas com foco na detecção precoce da IRC, especialmente em pacientes com risco aumentado de desenvolver a doença, incluindo-se nesse grupo hipertensos, diabéticos, pacientes portadores de doença cardiovascular e pessoas com história familiar de IRC.

Os rins exercem múltiplas funções que podem ser didaticamente caracterizadas como filtração, reabsorção, homeostase, funções endocrinológica e metabólica. A função primordial dos rins é a manutenção da homeostasia, regulando o meio interno predominantemente pela reabsorção de substâncias e íons filtrados nos gloméru- los e excreção de outras substâncias. A fisiologia renal apresenta dados impressionantes desde a filtração até a formação final da urina (Tabela 1). A cada minuto esses órgãos recebem cerca de 1.200 a $1.500 \mathrm{ml}$ de sangue (os quais são filtrados pelos glomérulos) e geram 180 $\mathrm{ml} /$ minuto de um fluido praticamente livre de células e proteínas, tendo em vista que essa membrana biológica permite a passagem de moléculas de até $66 \mathrm{kDa}$. Os túbulos proximal e distal, a alça de Henle e o ducto coletor se encarregam de reabsorver e secretar íons e outras substâncias, garantindo o equilíbrio homeostático, tudo isso regulado por uma série de hormônios, destacando-se o sistema renina-angiotensina-aldosterona e o hormônio antidiurético $(A D H)$, além de outras substâncias, como o óxido nítrico(4).

Em geral, os exames laboratoriais que avaliam a função renal tentam estimar a taxa de filtração glomerular (TFG), definida como o volume plasmático de uma substância que pode ser completamente filtrada pelos rins em uma determinada unidade de tempo. A TFG é uma das mais importantes ferramentas na análise da função renal, sendo também um indicador do número de néfrons funcionais. Como medida fisiológica, ela já provou ser o mais sensível e específico marcador de mudanças na função renal.

Nosso estudo tem por objetivo revisar os atuais marcadores da função renal e apontar as perspectivas desse campo da medicina laboratorial. Neste artigo de revisão apresentaremos as dosagens atualmente disponíveis para a avaliação da função renal, incluindo marcadores de lesão tecidual. Além disso, discutiremos as fórmulas que estimam a TFG derivadas de dosagens laboratoriais.

\section{Tabela 1 Função renal - componentes plasmáticos filtrados, reabsorvidos e excretados}

\begin{tabular}{lcccc}
\hline Componente plasmático & Filtração (g/dia) & Excreção (g/dia) & Reabsorção (g) & $(\%)$ \\
$\mathrm{H}_{2} \mathrm{O}$ & 1.800 .000 & 1.800 & 178.200 & 99 \\
$\mathrm{Cl}^{-}$ & 630 & 5,3 & 625 & 99,2 \\
$\mathrm{Na}^{+}$ & 540 & 3,3 & 537 & 99,4 \\
Bicarbonato (HCO3-) $_{\text {Glicose }}$ & 300 & 0,3 & 300 & $\sim 100$ \\
Uréia & 140 & 0 & 140 & 100 \\
$\mathrm{~K}^{+}$ & 56 & 32 & 24 & 45 \\
Ácido úrico & 28 & 4 & 24 & 85,7 \\
Creatinina & 8,5 & 0,8 & 7,7 & 90,6 \\
\hline
\end{tabular}

*Entre $7 \%$ e $20 \%$ de sua concentração urinária corresponde à creatinina que é secretada ativamente. 


\section{Discussão}

\section{Avaliação laboratorial da função renal}

\section{Uréia}

Esse é o principal metabólito nitrogenado derivado da degradação de proteínas pelo organismo, sendo $90 \%$ excretados pelos rins e correspondendo a aproximadamente $75 \%$ do nitrogênio não-protéico excretado. $O$ restante da uréia é eliminado basicamente pelo trato gastrintestinal e pela pele.

A degradação das proteínas inicia-se com o processo de proteólise que, na maioria das vezes, é mediado enzimaticamente. Várias enzimas têm a capacidade de degradar as proteínas, algumas delas com ações bem específicas; outras, agindo em sítios comuns a todas as proteínas. Após a lise das proteínas em aminoácidos, a biossíntese da uréia se dá exclusivamente em processo hepático intracelular, no qual o nitrogênio contido no aminoácido é convertido em uréia por um ciclo enzimático.

Apesar de ser filtrada livremente pelo glomérulo, não ser reabsorvida nem secretada ativamente, a uréia é um fraco preditor da TFG, pois 40\%-70\% retornam para o plasma por um processo de difusão passiva, que é dependente do fluxo urinário. Logo, a estase urinária leva a um maior retorno de uréia ainda nos túbulos renais e a uma subestimação da TFG calculada pelo clearance de uréia. Outros fatores podem mudar significativamente os valores plasmáticos da uréia sem terem relação com a função renal, destacando-se a dieta e a taxa de produção hepática.

A principal utilidade clínica da uréia parece estar na determinação em conjunto com a creatinina. A razão uréia sérica/creatinina sérica pode indicar estados patológicos diferentes. Em valor abaixo do esperado ela pode ser encontrada em patologias como a necrose tubular aguda, baixa ingestão de proteínas, condições de privação alimentar ou redução da síntese de uréia por insuficiência hepática. A análise dessa razão elevada pode ser feita de forma dicotomizada com a creatinina dentro do valor de referência, indicando processos que levam a diminuição do fluxo sangüíneo renal, aumento na ingestão protéica, ou sangramento gastrintestinal; e com a creatinina acima do valor normal, denotando processos obstrutivos pós-renais, como tumores ou estenose de vias urinárias. Outra utilidade da uréia está na sua dosagem urinária, que pode fornecer informação crucial no campo da nutrição e tem sido utilizada em pacientes internados para monitoramento de dietas especiais.
A metodologia laboratorial mais usada para a dosagem de uréia baseia-se em métodos enzimáticos colorimétricos. A grande maioria deles emprega uma enzima que degrada a uréia (urease) e outra enzima acoplada que usa a amônia como substrato. É nessa fase que há o monitoramento da variação cromática para a determinação dos valores de uréia. Os métodos de química seca também têm sido descritos utilizando a urease. Poucos interferentes analíticos foram encontrados na determinação da uréia.

\section{Creatinina}

A creatinina é um produto residual da creatina. A transformação de creatina em creatinina acontece no tecido muscular, no qual $1 \%-2 \%$ da creatina livre se converte espontânea e irreversivelmente em creatinina todos os dias. Logo, a quantidade de creatinina produzida é dependente da massa muscular e não apresenta grandes variações diárias.

A creatinina é filtrada livremente no glomérulo. Ao contrário da uréia, a creatinina é ativamente secretada em uma pequena parcela, mas o suficiente para superestimar a TFG. A quantidade secretada não é constante e depende do indivíduo e da concentração plasmática desse analito, dificultando sobremaneira a determinação de uma constante de secreção. Em termos gerais, 7\%-10\% da creatinina presente na urina é secretada.

Apesar de superestimar a TFG e depender da massa muscular, o clearance de creatinina continua sendo um dos marcadores mais usados na avaliação da função renal. Ele pode ser dosado diretamente com uma amostra de sangue e outra de urina em 24 horas consecutivas, aplicando-se a fórmula TFG = (concentração urinária $\mathrm{X}$ volume)/concentração plasmática. Além de superestimar de forma não-linear a TFG, essa dosagem tem outro sério problema, comum a todos os serviços de medicina laboratorial, que é a dificuldade por parte do paciente em manter o hábito cotidiano ao longo do dia da dosagem e coletar corretamente a urina de 24 horas. Muitas aberrações já foram encontradas nesse aspecto, entre elas o uso de medicamentos que modificam as taxas de secreção tubular de creatinina, alteração na ingestão hídrica e, principalmente, a incompreensão das orientações laboratoriais para a coleta minutada. Apesar dos grandes esforços na elaboração de instruções para a coleta, nenhum desses formulários parece esclarecer completamente as dúvidas dos pacientes do laboratório clínico.

A fim de evitar a coleta de urina por 24 horas e a interferência da secreção ativa de creatinina pelos rins, algumas fórmulas que estimam a TFG foram desenvolvidas. Neste 
artigo comentaremos as duas mais freqüentemente utilizadas: uma é derivada do estudo Modification of Diet in Renal Desease (MDRD); a outra é a equação de CockcroftGault (Tabela 2). Ambas as equações derivam de relações empíricas e foram validadas em numerosos indivíduos.

A equação do estudo MDRD inclui muitas variáveis, entre elas creatinina sérica, uréia sérica, albumina, idade, gênero e raça. Essa equação, pela complexidade dos cálculos, requer relativo conhecimento de matemática ou um programa de computação capaz de realizar o cálculo. Apesar de os estudos conduzidos, principalmente nos Estados Unidos da América, demonstrarem que essa equação é mais eficaz em detectar alterações em pacientes na fase inicial da doença renal, a dificuldade de categorizar indivíduos brasileiros quanto à raça tem dificultado seu uso na população nacional. Além disso, outro problema é que a fórmula foi validada em apenas um laboratório e com o uso da metodologia enzimática, que apresenta valores diferentes da metodologia colorimétrica, atualmente a mais usada em nosso meio. Uma forma abreviada da equação também está disponível. Nela apenas a creatinina, a idade, o gênero e a raça são utilizados, excluindo-se a necessidade de pesar os pacientes. Porém, a obrigatoriedade de classificar os indivíduos por raça e a dificuldade em usar a metodologia enzimática mantêm as mesmas limitações da fórmula completa.

Há boa correlação entre função renal e resultados da fórmula de Cockcroft-Gault. Porém, essa equação tende a superestimar a TFG, já que é derivada do clearance de creatinina e carrega consigo essa desvantagem. Além do mais, requer o peso do paciente para seu cálculo.

Dois artigos recentes ${ }^{(5,6)}$ apresentam uma discussão bastante interessante sobre a liberação da estimativa da TFG no laudo do próprio exame de creatinina. O tópico veio à tona após a publicação de orientações feitas por sociedades médicas americanas no sentido da liberação dessa estimativa pela equação derivada do estudo MDRD. Mesmo sem fornecer um valor de quantificação absoluta, a prática não parece ter tido o efeito esperado, pois apenas $25 \%$ dos serviços avaliados nos Estados Unidos da América a adotaram.

A metodologia utilizada para a determinação na maioria dos laboratórios clínicos deriva, ainda, da reação descrita por Jaffe, em 1886, na qual a creatinina reage com picrato em um meio alcalino, formando um complexo de coloração vermelho-alaranjada. Embora a metodologia seja muito antiga, alguns passos da reação e a estrutura do produto final não são completamente compreendidos ${ }^{(7)}$. Entre seus muitos interferentes destacam-se ácido ascórbico, acetona, glicose e proteínas, sendo que os ensaios mais recentes derivados da metodologia de Jaffe utilizam procedimentos que minimizam esses interferentes ${ }^{(8-10)}$. Um avanço na dosagem de creatinina pode ser feito com o uso de métodos enzimáticos que, em geral, empregam enzimas degradantes da creatinina. Apesar de apresentar melhores resultados, o custo desse exame ainda é um limitante do seu uso na prática laboratorial|(11, 12). A química seca disponível no Brasil utiliza uma metodologia enzimática que permite o uso da fórmula MDRD e evita interferentes da metodologia picrato em meio alcalino.

\section{Cistatina C}

A cistatina C é uma proteína inibidora da proteinase da cisteína e apresenta propriedades interessantes: tem baixo peso molecular (13 kDa com 122 aminoácidos), não é glicosilada, tem reação básica, é sintetizada por um gene expresso em todas as células nucleadas e tem ritmo constante de produção $0^{(13)}$. Todas essas peculiaridades juntas propiciam a sua utilização como marcador da função renal, já que ela é livremente filtrada pelos glomérulos. Uma das suas características mais interessantes é que, depois de filtrada, ela é completamente reabsorvida e metabolizada, não sendo excretada na urina nem retornando à corrente

\section{Tabela 2 Função renal - Equações para estimativa da TFG}

\section{Fórmulas}

\begin{tabular}{|c|c|}
\hline Equação de Cockcroft-Gault & $\begin{array}{l}{[140-\text { idade }(\text { anos }) \times \text { peso }(\mathrm{kg})] / 72 \times \text { creatinina sérica }(\mathrm{mg} / \mathrm{dl}) \times[0,85 \text { se a }} \\
\text { paciente for do sexo feminino }]\end{array}$ \\
\hline Equação MDRD completa & $\begin{array}{l}170 \times[\text { creatinina sérica }(\mathrm{mg} / \mathrm{dL})]^{-0,999} \times[\text { idade }]^{-0,176} \times[0,762 \text { se a paciente for } \\
\text { do sexo feminino } \times[1,18 \text { se o paciente for negro }] \times[\text { uréia sérica }(\mathrm{mg} / \mathrm{dl})]^{-0,17} \times \\
\text { [albumina sérica }(\mathrm{g} / \mathrm{dl})]^{0,318}\end{array}$ \\
\hline Equação MDRD abreviada & $\begin{array}{l}186 \times[\text { creatinina sérica }(\mathrm{mg} / \mathrm{dl})]^{-1,154} \times[\text { idade }]^{-0,203} \times[0,742 \text { se a paciente for do } \\
\text { sexo feminino } \times[1,21 \text { se o paciente for negro }]\end{array}$ \\
\hline
\end{tabular}


circulatória ${ }^{(14)}$. Sendo assim, esse marcador endógeno poderia estimar a TFG sem a necessidade de dosagem urinária, dispensando a coleta minutada de urina e solucionando um dos principais problemas dos outros marcadores endógenos da TFG. Outra vantagem da cistatina C é que não há variação significativa de intervalos de referência entre população masculina e feminina, em função de sua produção ser constante em todos os tecidos do organismo, diferente da creatinina, que depende da massa muscular.

Muitos estudos validaram o uso da cistatina $\mathrm{C}$ em indivíduos adultos saudáveis ${ }^{(15-17)}$ e em portadores de variadas doenças renais com TFG em todos os níveis ${ }^{(18-20)}$. A correlação da cistatina $\mathrm{C}$ com diversos marcadores exógenos de TFG apresenta coeficientes muito interessantes entre os níveis séricos de cistatina $\mathrm{C}$ e TFG mensurada por esses métodos, indiscutivelmente melhores que o da creatinina sérica(21-24). Além disso, outros estudos validam o uso de cistatina $\mathrm{C}$ em populações pediátricas ${ }^{(25,26)}$.

O primeiro ensaio laboratorial para dosagem de cistatina C, em 1979, utilizou radioimunoensaio(27). Desde então, outros métodos radiométricos, ensaios fluorimétricos $\mathrm{e}$ imunoquímicos foram desenvolvidos. Atualmente, imunoensaios homogêneos automatizados, utilizando partículas de látex ou poliestireno ligadas a anticorpos monoclonais específicos contra cistatina $\mathrm{C}$, afiguram-se como a metodologia mais adequada para rotinas laboratoriais.

Apesar de ser reconhecidamente um avanço da medicina laboratorial, a dosagem de cistatina $\mathrm{C}$ ainda é muito pouco utilizada. O custo do exame e a não-inserção do procedimento laboratorial nas principais tabelas dos planos de assistência suplementar de saúde inviabilizam o seu uso clínico. Contudo, acreditamos que em breve conseguiremos incluir esse procedimento nas tabelas e viabilizar esse avanço para seu completo uso médico.

\section{Avaliação laboratorial da lesão renal}

\section{Proteinúria}

Em indivíduos saudáveis é possível detectar uma quantidade de até $150 \mathrm{mg}$ de proteína durante um período correspondente a um dia. Em torno de 200 proteínas diferentes (derivadas tanto do plasma quanto do próprio trato urinário) podem estar presentes na urina. Proteínas com peso molecular inferior a $60 \mathrm{kDa}$ são filtradas livremente pelos glomérulos e logo reabsorvidas nos túbulos proximais. Dessa forma, condições que aumentem a quantidade de proteínas no filtrado glomerular ou diminuam a reabsorção tubular levam a proteinúria.
Didaticamente, a proteinúria pode ser dividida em padrões: o padrão glomerular é caracterizado pela perda da albumina sérica na urina junto com proteínas de tamanho semelhante, como antitrombina, transferrina, pré-albumina, a1-glicoproteína ácida e $\alpha 1$-antitripsina. Nesse padrão, pode ser detectada a gravidade do dano glomerular quando da presença de proteínas maiores, como a $\alpha 2$-macroglobulina e a lipoproteína $\beta$. Em geral, o padrão eletroforético das proteínas urinárias na lesão glomerular é bastante semelhante ao encontrado no plasma. Por isso, é recomendada a realização simultânea de eletroforese de proteínas séricas e urinárias. O padrão tubular é caracterizado pela perda protéica, em geral inferior a $1 \mathrm{~g} / \mathrm{dia}$. As proteínas presentes na urina são as de baixo peso molecular, que são livremente filtradas pelos glomérulos e não são reabsorvidas nos túbulos devido ao distúrbio de base. As proteínas mais comumente observadas nesse caso são $\alpha 1$-microglobulina, $\beta 2$-microglobulina, globulinas $\beta$ e as cadeias leves de imunoglobulinas. O padrão de aumento de fluxo é visto em pessoas que aumentam o nível sérico de certas proteínas. É observado em hemólise intravascular (hemoglobina), rabdomiólise (mioglobina), ou em gamopatias monoclonais como o mieloma múltiplo (imunoglobulinas). Inicialmente, essas proteínas não estão associadas a doença renal, mas podem levar a necrose tubular devido ao aumento da concentração intracelular nos túbulos proximais, posteriormente ocasionando dano celular. Vale ressaltar que muitas vezes a classificação didática desses padrões fica comprometida pela presença simultânea de mais de um padrão, e que em toda eletroforese de proteínas urinárias, a eletroforese sérica é indispensável para a interpretação clínica dos resultados, devendo ser realizada em paralelo.

Muitos são os métodos quantitativos usados para detectar a presença de proteínas na urina. Entre eles, podemos citar o azul de Coomassie, Ponceau S, cloridrato de benzentônio, molibdato de pirogalol vermelho. Todos apresentam bons resultados analíticos, devendo ser acompanhados com testes de proficiência interlaboratorial e controles internos. É importante salientar que as fitas de urina em geral são específicas para detecção de albumina e não de proteínas totais, podendo apresentar resultados divergentes do encontrado em análises quantitativas, por não detectar a presença de proteínas no padrão tubular (não há excreção urinária de albumina) e por apresentar resultados falso-positivos em amostras contaminadas por detergentes. Sendo assim, recomendamos métodos quantitativos na análise da proteinúria e confirmação quantitativa em pacientes que apresentem fita de urina reagente para presença de proteínas em amostra isolada. 


\section{Dismorfismo eritrocitário}

A análise da morfologia dos eritrócitos por microscopia de contraste de fase já vem sendo usada há algumas décadas para determinar o local da lesão tecidual produtora do sangramento urinário ${ }^{(28,29)}$. O mecanismo fisiopatológico capaz de explicar esse fenômeno envolveria a deformação do arcabouço celular dos eritrócitos na passagem pela membrana glomerular lesada.

A princípio foi proposta a classificação pelo percentual de eritrócitos dismórficos encontrados no exame de sedimento urinário, independentemente da morfologia eritrocitária, isto é, qualquer forma dismórfica (esquizócitos, anulócitos, equinócitos, estomatócitos, codócitos, acantócitos) seria considerada na contagem percentual e um ponto de corte determinando a origem das hemácias seria estabelecido. Esse ponto de corte apresentou um amplo intervalo, variando, a depender do grupo de pesquisadores envolvidos, entre $10 \%$ e $80 \%(30,31)$.

No início da década de 90, com a presença da discrepância entre os pontos de corte no percentual das hemácias dismórficas e da falsa positividade em alguns testes, foi proposta uma classificação mais específica na análise do sedimento urinário. Os acantócitos, os eritrócitos com forma anelar e as protrusões vesiculares (Figura 1) vistos à microscopia de contraste de fase foram acatados como uma forma mais específica de lesão glomerular confirmada por biópsia renal ${ }^{(32)}$. Estudo recente propõe ainda a subclassificação dessa célula e a relaciona com o grau de lesão renal|(33).

A baixa complexidade e o baixo custo fazem desse exame não-invasivo uma boa ferramenta laboratorial na análise de lesão renal. As ressalvas ficam por conta de ser um exame dependente de observador, além da sensibilidade em detectar a lesão glomerular (abaixo dos $80 \%$ ).

\section{Microalbuminúria}

A microalbuminúria é definida como a presença de 30 a $300 \mathrm{mg}$ de albumina na urina de 24 horas, ou uma taxa de excreção de 20 a $200 \mu \mathrm{g}$ de albumina por minuto ${ }^{(34)}$. O mecanismo fisiopatológico que explicaria a microalbuminúria está embasado em um processo inflamatório sistêmico

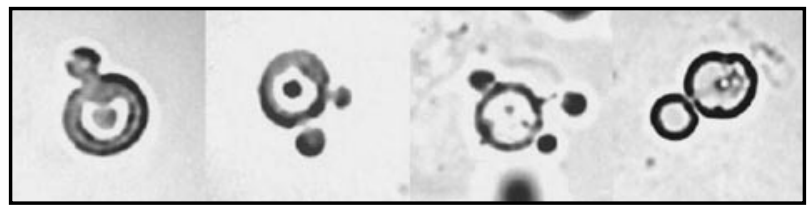

Figura 1- Acantócitos vistos à microscopia de contraste de fase que levaria a uma disfunção endotelial e um conseqüente aumento da permeabilidade capilar ${ }^{(35)}$.

A utilização clínica da microalbuminúria como marcador inicial de lesão renal começou na década de 80, após o desenvolvimento de metodologias com melhor sensibilidade analítica para a dosagem de albumina. Em pacientes diabéticos do tipo 1, esse marcador encontrado em dosagens subseqüentes indica a presença de nefropatia diabética em estágio pré-clínico ${ }^{(36)}$. A Associação Americana de Diabetes (ADA) recomenda acompanhamento desse grupo de pacientes com a realização anual do exame ${ }^{(34)}$. No diabetes tipo 2 a microalbuminúria tem menor relevância clínica, pois em muitos casos a doença já está acompanhada de lesão renal em estágios mais avançados com albuminúria franca, ou associada à hipertensão, que dificulta a identificação da causa da microalbuminúria. Mesmo assim, aqueles pacientes que não apresentarem albuminúria franca devem realizar a dosagem anualmente ${ }^{(34)}$. A utilização desse marcador pode ser feita ainda em pacientes hipertensos, pois ele está associado à morbimortalidade nesse grupo de pacientes ${ }^{(37)}$ e é marcador prognóstico na terapia clínica(38).

Dois estudos recentes ${ }^{(39,40)}$ demonstram que valores abaixo do ponto de corte para definição de microalbuminúria também estão associados a mortalidade por doença cardiovascular. Entretanto, nenhuma indicação de mudança foi feita pelas sociedades médicas. Acreditamos que, em breve, caso esses resultados venham a se confirmar, poderá ser revista a definição de microalbuminúria.

A metodologia mais utilizada na prática laboratorial para a dosagem da microalbuminúria é a imunométrica (em geral nefelometria ou turbidimetria) e, em menor freqüência, a radiometria. Porém, as duas tendem a subestimar o real valor da albumina, pois no ambiente urinário ou na passagem pela membrana glomerular inflamada podem ocorrer alterações da estrutura protéica dessa molécula impedindo a sua interação com o anticorpo. Por isso, a cromatografia líquida de alta performance continua sendo a maneira mais eficaz de mensurar a albumina em pequenos níveis(41). Esse método é pouco usado na prática clínica devido a seu alto custo de implantação e de aparelhagem, além da complexidade do procedimento. Outras situações clínicas podem levar à microalbuminúria transitória sem relevância médica. As mais comuns são a presença de processo infeccioso urinário, febre, insuficiência cardíaca, hiperglicemia e a realização de exercícios físicos. Tais dados devem ser levados em conta na interpretação do resultado do exame, e um teste confirmatório deve ser realizado quando necessário. 


\section{Proteínas ligadas a ácidos graxos: fração hepática}

A fração hepática das proteínas ligadas a ácidos graxos (L-FABP) é um grupo de proteínas intracelulares pertencentes à família das lipocalinas. Elas desempenham um papel fundamental no transporte intracelular de ácidos graxos livres no túbulo proximal após reabsorção conjunta desses ácidos com a albumina ${ }^{(42)}$. A L-FABP está expressa no túbulo proximal, e sua presença na urina está associada à lesão tubulointersticial renal. Um exemplo elucidativo seria a isquemia renal, a qual promoveria aumento do estresse oxidativo, levando à oxidação dos ácidos graxos ligados a essas proteínas. Nesse complexo, as espécies reativas de oxigênio lesariam a membrana celular, permitindo a saída das L-FABP para o lúmen do túbulo proximal e a posterior excreção urinária.

A vantagem desse marcador é sua especificidade renal. Marcadores tradicionais que são usados atualmente, como proteinúria, albuminúria e clearance de creatinina, estão baseados na produção endógena à distância, ao contrário da L-FABP $\left.{ }^{(43}\right)$. Ademais, nos testes tradicionais, a idade, o sexo, a massa muscular e patologias não-renais podem interferir no resultado. Outro avanço com o uso da L-FABP é que, em geral, os marcadores medem principalmente a TFG ou lesão glomerular, ao passo que as L-FABP estão associadas com o seguimento tubulointersticial, que para alguns autores é mais relevante na análise da função renal(44).

A utilidade clínica desse novo marcador está sendo estudada. Somente no ano de 2005, 11 publicações trataram do tema. Nesses estudos a L-FABP mostrou ter aplicabilidade clínica em diabetes do tipo 2 , doença glomerular crônica, doença renal policística, glomeruloesclerose focal, nefropatia por IgA, nefropatia induzida por contraste radiológico, choque séptico, após transplante em doadores renais, e em crianças prematuras ${ }^{(43)}$. Como todo novo exame laboratorial, a evidência científica deve ser o principal fator na sua validação. Nos próximos anos deveremos ver uma investigação mais profunda dessa promissora dosagem.

O único método comercial disponível para a dosagem de L-FABP é o ensaio imunossorvente ligado à enzima (ELISA). Esse método requer um pré-tratamento da amostra urinária para posterior reação, a qual se processa em duas fases. Na primeira, com anticorpo, fixa a L-FABP no poço de reação que, em seguida, é marcado com um anticorpo conjugado. Uma reação final catalisada pelo conjugado gera uma coloração que é determinante da concentração do analito em questão.

\section{Conclusão}

Nas últimas décadas, numerosos avanços foram feitos no desenvolvimento de marcadores laboratoriais de função e lesão renal. Muitos deles já foram validados e estão sendo empregados amplamente no auxílio de diagnóstico, monitoramento terapêutico, análise de progressão das doenças renais, e prognóstico destas e de outras patologias. Outros se encontram em fase inicial de desenvolvimento e, ao longo dos próximos anos, certamente estarão disponíveis como novas ferramentas clínicas e propedêuticas. Apesar de tudo, muito há de ser feito ainda nesse campo. Como já descrito, nenhum desses exames pode suprir por si só todas as necessidades médicas. Todos apresentam pontos em que deixam a desejar. Sendo assim, é necessário usá-los com cautela e em geral em conjunto, nunca esquecendo as peculiaridades e aplicabilidades de cada um dos testes aqui apresentados e descritos em numerosos consensos e guidelines das sociedades médicas, que tentam normatizar e aplicar os conhecimentos científicos baseados em evidências. Acreditamos que só assim o conhecimento da medicina laboratorial poderá evoluir de forma contínua e segura.

\section{Referências}

1. JAFFE, M. Z. Methods determining creatinine. Physiol Chem, v. 10, p. 39-40, 1886.

2. LEITE, I.C. et al. Comparação das informações sobre as prevalências de doenças crônicas obtidas pelo suplemento saúde da PNAD/98 e as estimadas pelo estudo Carga de Doença no Brasil. Ciênc Saúde Coletiva, v. 7, n. 4, p. 733-41, 2002.
3. CORESH, J. et al. Chronic kidney disease awareness, prevalence, and trends among U.S. adults, 1999 to 2000. J Am Soc Nephrol, v. 16, p. 180-88, 2005.

4. BURTIS, C.A.; ASHWOOD, E.R. Clinical Chemistry. Philadelphia: Saunders, 1999.

5. LEVEY, A.S.; STEVENS L.A.; HOSTETTER, T. Automatic reporting of estimated glomerular filtration rate: just 
what the doctor ordered. Clin Chem, v. 52, n. 12, p. 2188-93, 2006.

6. RAINEY, P.M. Automatic reporting of estimated glomerular filtration rate: jumping the gun? Clin Chem, v. 52, n. 12, p. 2184-87, 2006.

7. VASILIADES, J. Reaction of alkaline sodium picrate with creatinine: I. Kinetics and mechanism of formation of the mono-creatinine picric acid complex. Clin Chem, v. 22, p. 1664-71, 1976

8. BOWERS, L. D. Kinetic serum creatinine assays I. The role of various factors in determining specificity. Clin Chem, v. 26, p. 551-4, 1980.

9. SWAIN, R.R.; BRIGGS, S.L. Positive interference with the Jaffe reaction by cephalosporin antibiotics. Clin Chem, v. 23, p. 1340-42, 1977

10. WATKINS, P.J. The effect of ketone bodies on the determination of creatinine. Clin Chim Acta, v. 18, n. 2, p. 191-96, 1967.

11. SPAYD, R.W. et al. Multilayer film elements for clinical analysis: applications to representative chemical determinations. Clin Chem, v. 24, p. 1343-50, 1978.

12. GRAY, M.R. et al. Evaluation of a rapid specific ward based assay for creatinine in blood. Clin Nephrol, v. 43, n. 3, p. 169-73, 1995.

13. ABRAHAMSON, M. et al. Structure and expression of the human cystatin C gene. Biochem J, v. 268, p. 287-94, 1990.

14. GRUBB, A. Diagnostic value of analysis of cystatin $C$ and protein $\mathrm{HC}$ in biological fluids. Clin Nephrol, v. 38, p. S20-S27, 1992.

15. NORLUND, L. et al. Reference intervals for the glomerular filtration rate and cell-proliferation markers: serum cystatin $\mathrm{C}$ and serum $\beta 2$-microglobulin/cystatin C-ratio. Scand J Clin Lab Invest, v. 57, p. 463-70, 1997.

16. ERLANDSEN, E.J.; RANDERS, E.; KRISTENSEN, J.H. Reference intervals for serum cystatin $C$ and serum creatinine in adults. Clin Chem Lab Med, v. 36, p. 393-97, 1998.

17. FINNEY, H.; NEWMAN, D.J.; PRICE, C.P. Adult reference ranges for serum cystatin $\mathrm{C}$, creatinine and predicted creatinine clearance. Ann Clin Biochem, v. 37, p. 4959, 2000.

18. FLISER, D.; RITZ, E. Serum cystatin C concentration as a marker of renal dysfunction in the elderly. Am J Kidney Dis, v. 37, p. 79-83, 2001.

19. HERGET-ROSENTHAL, S. et al. Cystatin C: efficacy as screening test for reduced glomerular filtration rate. Am J Nephrol, v. 20, p. 97-102, 2000.

20. LE BRICON, T. et al. Changes in plasma cystatin $\mathrm{C}$ after renal transplantation and acute rejection in adults. Clin Chem, v. 45, p. 2243-49, 1999.

21. WOITAS, R.P. et al. Correlation of serum concentrations of cystatin $C$ and creatinine to inulin clearance in liver cirrhosis. Clin Chem, v. 46, p. 712-14, 2000.

22. TOMINO, Y. et al. Serum cystatin $C$ may predict the prognostic stages of patients with IgA nephropathy prior to renal biopsy. J Clin Lab Anal, v. 15, p. 25-29, 2001.

23. MANGGE, H. et al. Cystatin $\mathrm{C}$, an early indicator for incipient renal disease in rheumatoid arthritis. Clin Chim Acta, v. 300, p. 195-202, 2000.

24. CAREGARO, L. et al. Limitations of serum creatinine level and creatinine clearance as filtration markers in cirrhosis. Arch Intern Med, v. 154, p. 201-05, 1994.

25. HARMOINEN, A. et al. Reference intervals for cystatin $C$ in pre- and full-term infants and children. Pediatr Nephrol, v. 15, p. 105-08, 2000.

26. FINNEY, $H$. et al. Reference ranges for plasma cystatin $\mathrm{C}$ and creatinine measurements in premature infants, neonates, and older children. Arch Dis Child, v. 82, p. 71-75, 2000.

27. LOFBERG, H.; GRUBB, A.O. Quantitation of gamma-trace in human biological fluids: indications for production in the central nervous system. Scand J Clin Lab Invest, v. 39, p. 619-26, 1979.

28. CHANG, B.S. Red cell morphology as a diagnostic aid in hematuria. JAMA, v. 252, p. 1747-9, 1984.

29. BIRCH, D.F.; FAIRLEY, K.F. Haematuria: glomerular or non-glomerular? Lancet, v. 20, p. 845-46, 1979.

30. BIRCH, D.F. et al. Urinary erythrocyte morphology in the diagnosis of glomerular hematuria. Clin Nephrol, v. 20, p. 78-84, 1983.

31. FASSETT, R.G.; HORGAN, B.A.; MATHEW, T.H. Detection of glomerular bleeding by phase-contrast microscopy. Lancet, v. 26, p. 1432-4, 1982.

32. KOHLER, H.; WANDEL, E.; BRUNCK, B. Acanthocyturia: a characteristic marker for glomerular bleeding. Kidney Int, v. 40, p. 115-20, 1991.

33. HEINE, G.H. et al. Acanthocytes in the urine: useful tool to differentiate diabetic nephropathy from glomerulonephritis? Diabetes Care, v. 27, p. 190-94, 2004.

34. AMERICAN DIABETES ASSOCIATION. Diabetic nephropathy (position statement). Diabetes Care, v. 25, p. S85-89, 2002.

35. STUVELING, E.M. et al. C-reactive protein modifies the relationship between blood pressure and microalbuminuria. Hypertension, v. 43, p. 791-6, 2004.

36. MOGENSEN, C.E.; CHRISTENSEN, C.K. Predicting diabetic nephropathy in insulin-dependent patients. $N$ Engl J Med, v. 311, p. 89-93, 1984.

37. GERSTEIN, H.C. et al. Albuminuria and risk of cardiovascular events, death, and heart failure in diabetic and nondiabetic individuals. JAMA, v. 286, p. 421-26, 2001.

38. SCHRADER, J. et al. Microalbuminuria and tubular proteinuria as risk predictors of cardiovascular morbidity and mortality in essential hypertension: final results of a prospective long-term study (MARPLE Study). J Hypertens, v. 24, p. 541-48, 2006.

39. ROMUNDSTAD, S. et al. Microalbuminuria and all-cause mortality in 2,089 apparently healthy individuals: a 
4.4-year follow-up study. The Nord-Trondelag Health Study (HUNT), Norway. Am J Kidney Dis, v. 42, p. 466-73, 2003.

40. KLAUSEN, K.P. et al. New definition of microalbuminuria in hypertensive subjects: association with incident coronary heart disease and death. Hypertension, v. 46, p. 33-37, 2005.

41. COMPER, W.D. et al. Earlier detection of microalbuminuria in diabetic patients using a new urinary albumin assay. Kidney Int, v. 65, p. 1850-5, 2004.
42. HEWITT, S.M.; DEAR, J.; STAR, R.A. Discovery of protein biomarkers for renal diseases. J Am Soc Nephrol, v. 15, p. 1677-89, 2004.

43. KAMIJO, A. et al. Clinical evaluation of urinary excretion of liver-type fatty acid-binding protein as a marker for the monitoring of chronic kidney disease: a multicenter trial. J Lab Clin Med, v. 145, p. 125-33, 2005.

44. KAMIJO, A. et al. Urinary free fatty acids bound to albumin aggravate tubulointerstitial damage. Kidney Int, v. 62, p. 1628-37, 2002. 